Article

\title{
Effect of Hydrophilic Polymers on Complexation Efficiency of Cyclodextrins in Enhancing Solubility and Release of Diflunisal
}

\author{
Mehreen Bashir ${ }^{1}$, Haroon Khalid Syed ${ }^{1, *} \mathbb{1}$, Sajid Asghar ${ }^{1}$, Muhammad Irfan ${ }^{1}$, \\ Waleed Hassan Almalki ${ }^{2}$, Salah Ali Menshawi ${ }^{3}$, Ikram Ullah Khan ${ }^{1}$ (D) Pervaiz A. Shah ${ }^{4}$, \\ Ikrima Khalid ${ }^{1}$, Junaid Ahmad ${ }^{1}$, Umar Farooq Gohar ${ }^{5}$, Kok Khiang Peh ${ }^{6, *}$ and \\ Muhammad Shahid Iqbal ${ }^{7}$
}

1 Department of Pharmaceutics, Faculty of Pharmaceutical Sciences, Government College University Faisalabad, Faisalabad 38000, Pakistan; mehreen.bashir@yahoo.com (M.B.); sajuhappa@gmail.com (S.A.); manipharma1@gmail.com (M.I.); ikramglt@gmail.com (I.U.K.); ikrima_khalid@gmail.com (I.K.); khawajajunaid93@gmail.com (J.A.)

2 Department of Toxicology and Pharmacology, College of Pharmacy, Umm Al Qura University, Makkah 21955, Saudi Arabia; whmalki@uqu.edu.sa

3 Department of Toxicology in Comprehensive Specialized Clinics Security Forces, Jeddah 21442, Saudi Arabia; captenmd2001@yahoo.com

4 University College of Pharmacy, University of the Punjab, Lahore 54590, Pakistan; pashah6512@yahoo.com

5 Institute of Industrial Biotechnology, Government College University, Lahore 54590, Pakistan; dr.mufgohor@gcu.edu.pk

6 Department of Pharmaceutical Technology, School of Pharmaceutical Sciences, Universiti Sains Malaysia, Minden, Penang 11800, Malaysia

7 Department of Clinical Pharmacy, College of Pharmacy, Prince Sattam Bin Abdulaziz University, Alkharj 11942, Saudi Arabia; drmmsiqbal@gmail.com

* Correspondence: syedharoonkhalid@gcuf.edu.pk or haroonkhalid80@gmail.com (H.K.S.); kkpeh@usm.my or kkpehken@gmail.com (K.K.P.)

Received: 10 June 2020; Accepted: 7 July 2020; Published: 15 July 2020 updates

\begin{abstract}
The effects of three hydrophilic polymers, namely, carboxymethyl cellulose sodium (CMC-Na), polyvinyl alcohol (PVA) and poloxamer-188 (PXM-188) on the solubility and dissolution of diflunisal (DIF) in complexation with $\beta$-cyclodextrin $(\beta C D)$ or hydroxypropyl $\beta$-cyclodextrin $(\mathrm{HP} \beta C \mathrm{C})$, were investigated. The kneading method was used at different drug to cyclodextrin weight ratios. Increases in solubility and drug release were observed with the $D I F / \beta C D$ and DIF/HP $\beta C D$ complexes. The addition of hydrophilic polymers at 2.5, 5.0 and $10.0 \% \mathrm{w} / \mathrm{w}$ markedly improved the complexation and solubilizing efficiency of $\beta C D$ and HP $\beta C D$. Fourier-transform infrared (FTIR) showed that DIF was successfully included into the cyclodextrin cavity. Differential scanning calorimetry (DSC) and X-ray diffractometry (XRD) confirmed stronger drug amorphization and entrapment in the molecular cage of cyclodextrins. The addition of PVA, CMC-Na or PXM-188 reduced further the intensity of the DIF endothermic peak. Most of the sharp and intense peaks of DIF disappeared with the addition of hydrophilic polymers. In conclusion, PXM-188 at a weight ratio of $10.0 \% \mathrm{w} / \mathrm{w}$ was the best candidate in enhancing the solubility, stability and release of DIF.
\end{abstract}

Keywords: diflunisal; $\beta$-cyclodextrin; hydroxypropyl $\beta$-cyclodextrin; hydrophilic polymers; complexation; dissolution rate 


\section{Introduction}

The major challenges of BCS class II (low solubility and high permeability) drugs are poor aqueous solubility and dissolution [1-4]. Various techniques have been introduced to overcome the limitation of BCS Class II drugs, which include salt formation, lipid-based formulations, particle size reduction, solid dispersions and complexation with cyclodextrins or its derivatives [5-9]. Complexation of poorly soluble drugs with cyclodextrins has become one of the important approaches in formulation development [10-12]. Cyclodextrins exhibit basket-like structure with an outer hydrophilic surface, whereas the inner cavity is lipophilic. The whole molecule appears as a cone/torus shape due to limited rotation of bonds connecting the glucopyranose units, providing the opportunity to lodge a variety of suitably sized lipophilic drugs within the cavity [13]. Favorable modifications to the physicochemical properties of poorly soluble drugs, namely, solubility, stability, dissolution rate and bioavailability, could be achieved via complexation with cyclodextrins [14]. Although alpha, beta and gamma cyclodextrins (consisting of six, seven and eight glucopyranose units, respectively) are available, $\beta C D$ is the most extensively used, which could be attributed to the factors of price, cavity dimensions, approval status and availability $[15,16]$. Diflunisal is chemically $5-\left(2^{\prime}, 4^{\prime}\right.$-difluorophenyl) salicylic acid $\left(\mathrm{C}_{13} \mathrm{H}_{8} \mathrm{O}_{3} \mathrm{~F}_{2}\right)$. It is considered a new salicylic acid synthetic analog, in which the difluorophenyl group (at the $\mathrm{C} 5$ position of salicylic acid) is responsible for imparting lipophilic character to the molecule [17]. In the literature, the majority of the work was done on the analytical characterization of diflunisal, such as nuclear magnetic resonance studies and ion-selective electrode potentiometry [18-20]; however, Zugasti et al. (2009) developed a diflunisal binary system through a coevaporation technique by using a single ratio [21]. Solubility enhancement of DIF via the formation of solid dispersion with polyethylene glycol, inclusion complexes with polyethylene glycol (PEG) and poly e-caprolactone (PCL), solid dispersion with Eudragit RS 100 and RL 100, coprecipitates with PVP K30, $\beta C D$ inclusion complex, DIF-pyrazinamide and nicotinamide co-crystal were reported [22-27]. Enhancement in solubility and dissolution of DIF could ameliorate the bioavailability of DIF.

The addition of hydrophilic polymers was found to improve the solubilization and complexation efficiency of cyclodextrins [28]. In view of the favorable effect as a result of incorporation of hydrophilic polymers, PVA, CMC-Na, and PXM-188, were used for diflunisal in the present study. These hydrophilic polymers could ameliorate the solubilizing and complexation efficiency of cyclodextrins and their derivatives [29-31].

PVA maintains a higher concentration of the free drug at the target site, either by augmenting the drug solubility or by shifting the equilibrium between the free drug [D] and [D]-PVA-CD complex towards the former [32]. CMC-Na was reported to enhance the solubilizing efficiency of CDs, thus, improving the complexation efficiency between drug and carrier, as supported by previous data [33]. On the other hand, PXM-188 presents significant improvement in the dissolution profile by impeding the crystalline state of the drug, resulting in an amorphous form of the drug [34]. The purpose of the study was to investigate the effect of carboxymethyl cellulose sodium (CMC-Na), polyvinyl alcohol (PVA) and Poloxamer-188 (PXM-188), on the complexation efficiency of $\beta$-cyclodextrin ( $\beta C D)$ and hydroxypropyl $\beta$-cyclodextrin (HP $\beta C D$ ), in enhancing the solubility and release of a BCS Class II drug, diflunisal (DIF). The kneading method was used in the preparation of the inclusion complexes. The binary and ternary systems were characterized using scanning electron microscopy (SEM), Fourier-transform Infrared (FTIR), differential scanning calorimeter (DSC) and X-ray powder diffraction (XRD).

\section{Materials and Methods}

\subsection{Materials}

Diflunisal was supplied by AK Scientific (Union city, San Francisco, USA). Beta-cyclodextrin $(\beta C D)$ and hydroxypropyl $\beta$-cyclodextrin $(\mathrm{HP} \beta C D)$ were provided by Roquette (Lestrem, France). Carboxymethyl cellulose sodium (CMC-Na) and Poloxamer-188 (PXM-188) were purchased from 
Sigma-Aldrich (St. Louis, MO, USA). Polyvinyl alcohol (PVA) was purchased from Daejung (Siheung, Korea). All other materials were of analytical reagent grade and used as received.

\subsection{Phase Solubility Study}

Phase solubility study was conducted according to the method of Higuchi and Connors [35]. Diflunisal in excess amounts was added to $10 \mathrm{~mL}$ of aqueous solutions of varying concentrations of $\beta C D$ or $H P \beta C D$ with hydrophilic polymers $(0,2.5,5.0$ and $10.0 \% \mathrm{w} / \mathrm{v})$. The suspensions were placed in a shaking water bath at a temperature of $37^{\circ} \mathrm{C}$ for $72 \mathrm{~h}$ to reach equilibrium. After centrifuging at $6000 \mathrm{rpm}$ for $30 \mathrm{~min}$, the samples were filtered. The concentration of DIF in the sample was analyzed using a UV spectrophotometer (UV-1700, Shimadzu, Kyoto, Japan) at $251.5 \mathrm{~nm}$ after suitable dilution. The stability constant $(K s)$ and complexation efficiency (C.E) were calculated using the following equations [36].

$$
K s=\frac{\text { slope }}{\text { So(1-slope })}
$$

where So is the equilibrium solubility of DIF in water; slope is obtained from the plot of DIF concentration against $\beta C D$ or $\mathrm{HP} \beta C D$ concentrations with or without polymers.

$$
\text { C.E }=\frac{\text { slope }}{1-\text { slope }}
$$

\subsection{Preparation of Binary Complexes}

The binary inclusion complexes comprising DIF and $\beta C D$ or HP $\beta C D$ at 1:1, 1:2 and 1:4 weight ratios were prepared. The drug and cyclodextrins were kneaded in the presence of water and methanol (1:1) for $45 \mathrm{~min}$ followed by drying at $45^{\circ} \mathrm{C}$ for $24 \mathrm{~h}$. The dried mass was passed through a sieve (number 60) and stored in an air-tight container.

\subsection{Preparation of Ternary Complexes}

PVA, CMC-Na or PXM-188 at concentrations of 2.5, 5.0, 10.0\% w/w at dry weight of inclusion complexes were added to binary complexes comprising of DIF and $\beta C D$ or HP $\beta C D$ at a 1:2 ratio. The mixtures were kneaded in the presence of water: methanol (1:1) for $45 \mathrm{~min}$, followed by drying at $45{ }^{\circ} \mathrm{C}$ for $24 \mathrm{~h}$. The dried mass was then passed through a sieve (number 60) and stored in an air-tight container.

\subsection{Solubility Studies}

The cyclodextrin complexes were added into $20 \mathrm{~mL}$ distilled water in glass vials and vortex mixed for $3 \mathrm{~min}$. Then, the vials were placed in a shaking water bath at $30^{\circ} \mathrm{C}$ for $72 \mathrm{~h}$. The samples were filtered through a $0.45 \mu \mathrm{m}$ membrane filter and analyzed using UV-spectrophotometer (UV-1700, Shimadzu, Kyoto, Japan) at $251.5 \mathrm{~nm}$ after suitable dilution [37]. Each measurement was repeated in triplicate.

\subsection{In Vitro Diflunisal Dissolution Studies}

The in vitro dissolution studies were conducted using USP dissolution apparatus II (PTWS 3CE, Pharmatest, Hainburg, Germany) paddle method (USP XXXII, 2009). The dissolution medium was comprised of $900 \mathrm{~mL}$ of distilled water maintained at $37.0 \pm 0.5^{\circ} \mathrm{C}$ with a paddle speed of $100 \mathrm{rpm}$. The quantity of sample equivalent to $10 \mathrm{mg}$ of the drug was weighed accurately and added into each dissolution vessel. Samples of $5 \mathrm{~mL}$ were withdrawn at preset time intervals of 2.5, 5.0, 10.0, 15.0, 30.0, 45.0 and $60.0 \mathrm{~min}$, and refilled with fresh dissolution medium. The drug concentration in the sample was analyzed using a UV spectrophotometer (UV-1700, Shimadzu, Kyoto, Japan) at $251.5 \mathrm{~nm}$. Dissolution Efficiency (DE) was determined using trapezoidal method and expressed as percentage of 
the area of the rectangle divided by the area of $100 \%$ dissolution in the same time period. $\mathrm{DE} \%$ was calculated using the following equation.

$$
D E(\%)=\frac{\int_{0}^{t} y X d t}{y 100 X t} \times 100 \%
$$

where $y$ is the percentage of dissolved DIF; DE is the area under the dissolution curve between time points $t_{1}$ and $t_{2}$ expressed as a percentage of the curve at maximum dissolution, $y_{100}$, over the same period. It was computed to compare the performance of binary and ternary formulations [38]. The time taken for $50 \%$ drug release $\left(T_{50}\right)$ was obtained from the drug dissolution profiles.

\subsection{Scanning Electron Microscopy (SEM)}

The surface morphology of DIF, $\beta C D$, HP $\beta C D$, PVA, CMC-Na, PXM-188, binary inclusion complexes and ternary inclusion complexes was observed under scanning electron microscope (JSM-6480, Tokyo, Japan). Electrical conductivity was improved by sputtering a thin gold layer on the samples before imaging.

\subsection{Fourier-Transform Infrared Spectroscopy (FTIR)}

The infrared spectra of samples were obtained using FTIR (BRUKER-Tensor II-ALPHA, Berlin, Germany). The samples (10-50 mg) were directly placed on a sample pan and analyzed over a region from 4000 to $400 \mathrm{~cm}^{-1}$ with 10 scans, at a resolution of $1 \mathrm{~cm}^{-1}$ and wavenumber accuracy of $0.01 \mathrm{~cm}^{-1}$.

\subsection{Differential Scanning Calorimetry (DSC)}

The thermograms of samples were recorded using a differential scanning calorimeter (Universal V4.2E TA Instruments, Newcastle, DE, USA). A sample of $5 \mathrm{mg}$ was crimped in a covered sample pan and heated in an atmosphere of nitrogen $(20 \mathrm{~mL} / \mathrm{min})$ at a rate of $10^{\circ} \mathrm{C} / \mathrm{min}$ over the temperature range of $25-400{ }^{\circ} \mathrm{C}$. An empty aluminum pan was used as a reference.

\subsection{Powder X-ray Diffractometry (XRD)}

The diffraction pattern of samples was obtained using an X-ray powder diffractometer (Bruker D-8 Advance, Berlin, Germany). A sample of $10 \mathrm{mg}$ was packed in an aluminum sample container after slight grinding. The required conditions to obtain the diffraction pattern were as follows: Current $30 \mathrm{~mA}$, target $\mathrm{Cu}$, voltage $30 \mathrm{kV}$, filter $\mathrm{Ni}$, time constant $4 \mathrm{~s}$, scanning 5 to $60^{\circ} \mathrm{C}$, at increments of $0.02{ }^{\circ} \mathrm{C}$.

\subsection{Statistical Analysis}

The results were presented as mean \pm standard deviation (SD). The statistical analysis was performed using SPSS ${ }^{\circledR}$ (Version 16, USA). The solubility results were analyzed using one-way analysis of variance (ANOVA). When there was a statistically significant difference, a post hoc Tukey HSD (Honestly significant difference) test was performed. A statistically significant difference was considered at $p<0.05$.

\section{Results}

\subsection{Phase Solubility Study}

Figure 1a-d demonstrated the proportional increase in solubility of DIF with increases in $\beta C D$ or HP $\beta C D$ concentration. A comparatively higher solubility of DIF in HP $\beta C D$ than $\beta C D$ could be attributed to a relatively higher solubilization efficiency of $H P \beta C D$. The addition of hydrophilic polymers further improved the solubility. PXM-188 yielded the highest value of slope at the same concentration, thus, giving maximum drug solubility. The stability constant and complexation efficiency of both binary and ternary systems of $\beta C D$ and HP $\beta C D$ are shown in Table 1 . CMC formed gel at this 
concentration, and hence, was excluded from phase solubility. The ternary system produced more enhanced drug solubilization than the binary system, as indicated by their stability constant values. The reported value of stability constant for improved drug stability ranged from 200 to $5000 \mathrm{M}^{-1}$ [39]. It is favorable to measure complexation efficiency (C.E) as it is a more accurate term in relation to intrinsic solubility determination [40].

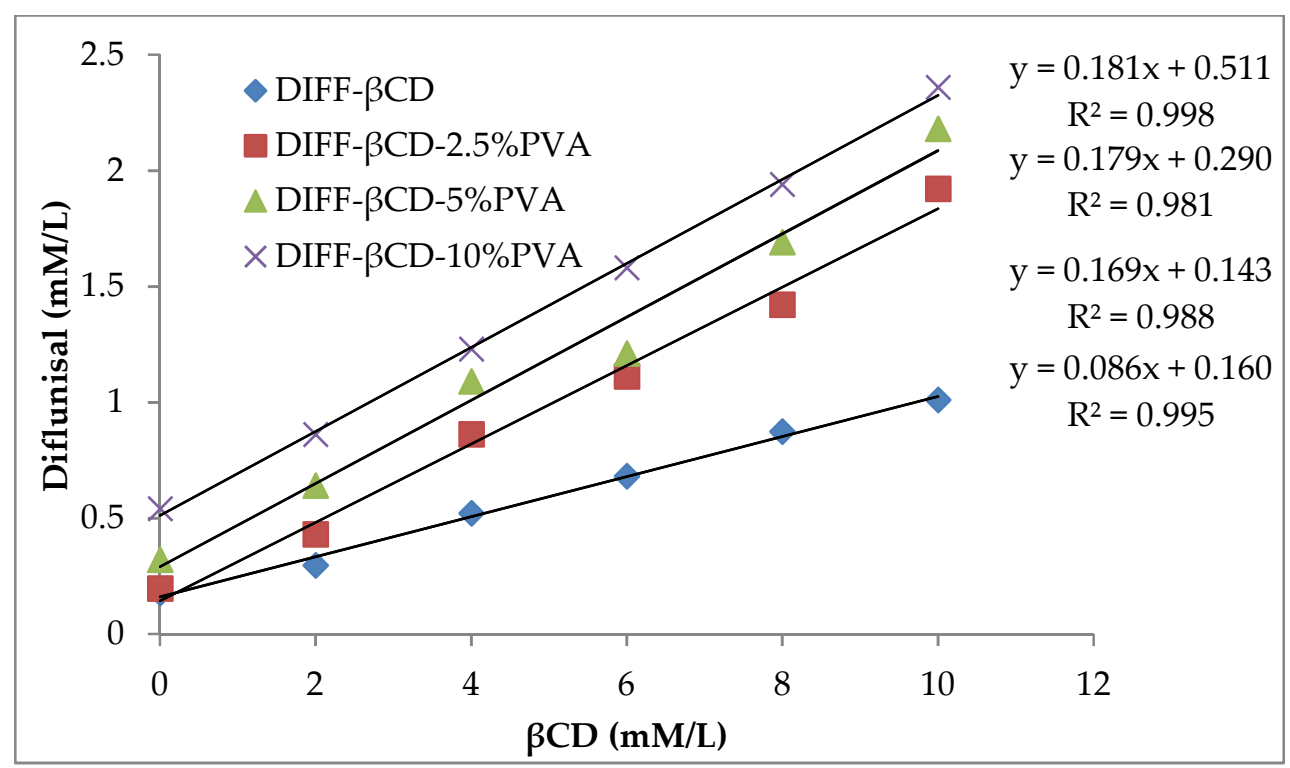

(a)

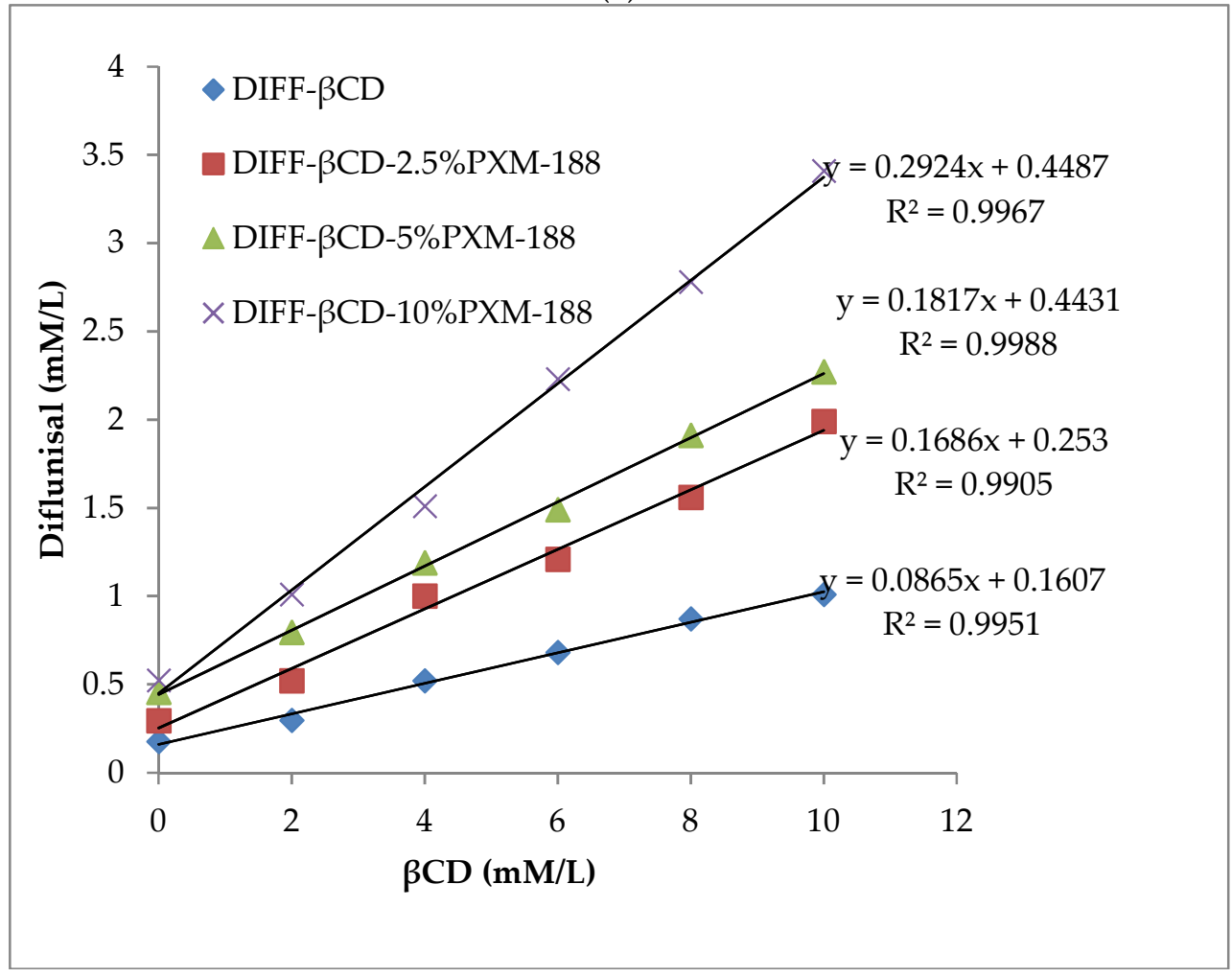

(b)

Figure 1. Cont. 


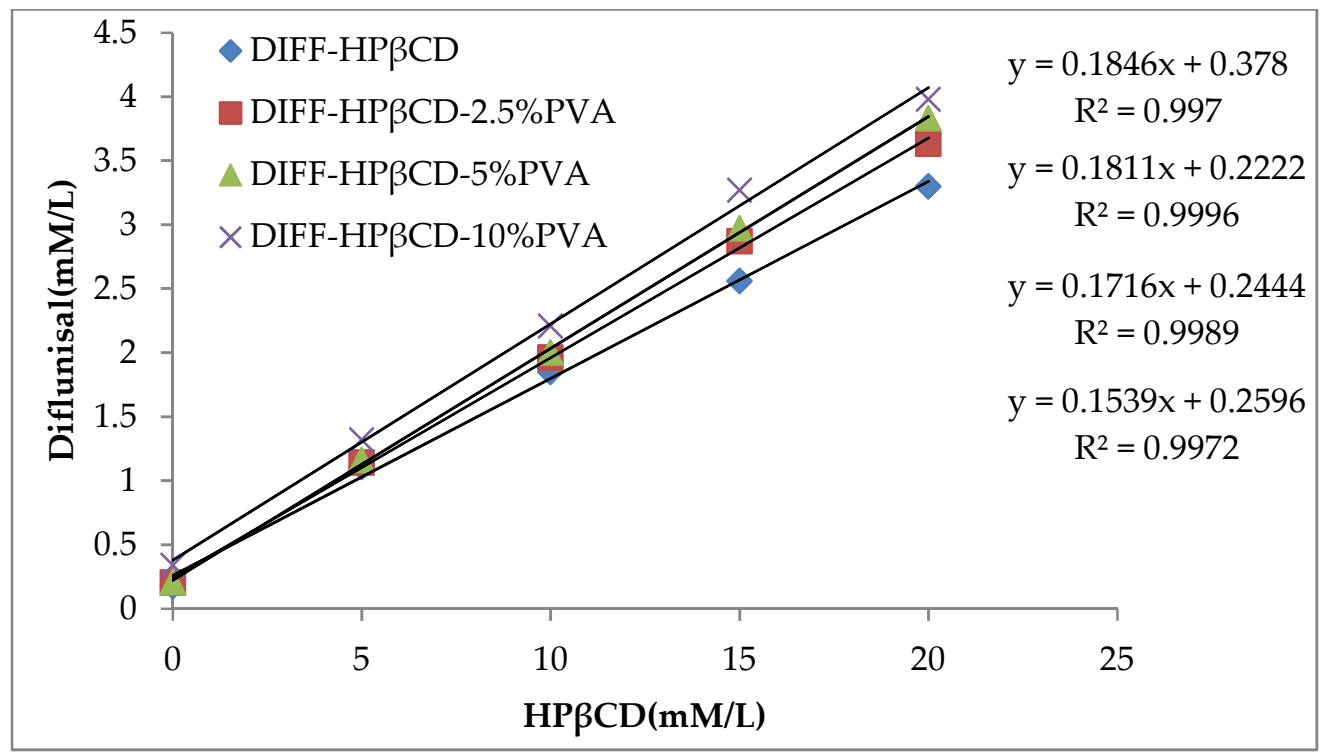

(c)

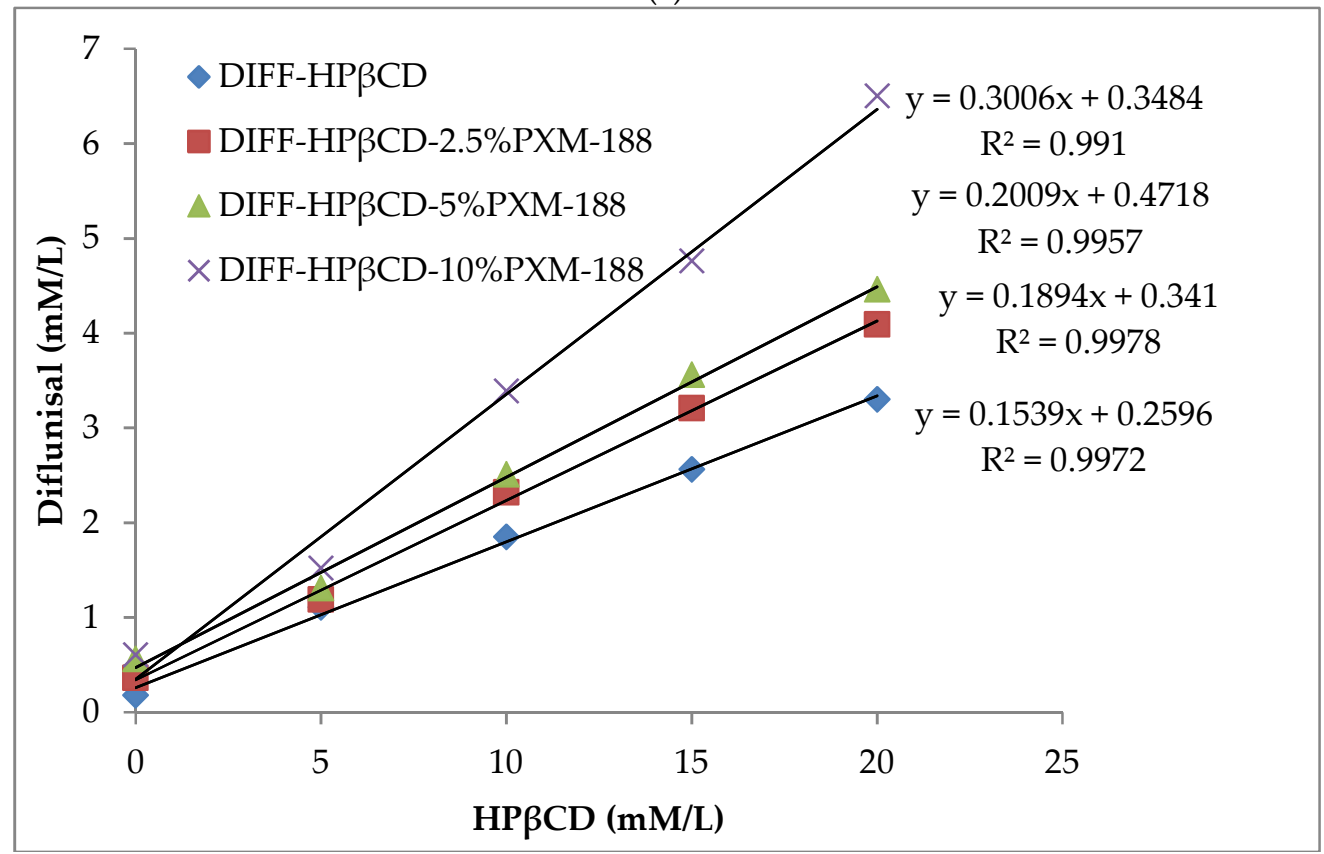

(d)

Figure 1. Phase solubility diagram of DIF in aqueous solution of $\beta C D$ with/without PVA (a); with/without PXM-188 (b); Phase solubility diagram of DIF in aqueous solution of HP $\beta$ CD with/without PVA (c); with/without PXM-188 (d). Mean \pm SD, $\mathrm{N}=3$. 
Table 1. Stability constant and complexation efficiency results of binary and ternary inclusion complexes.

\begin{tabular}{|c|c|c|}
\hline Inclusion Complexes & Stability Constant $\left(\mathbf{M}-{ }^{1}\right)$ & Complexation Efficiency \\
\hline DIF: $\beta C D$ & $528.6 \pm 1.0$ & 0.094 \\
\hline DIF: $\mathrm{HP} \beta C D$ & $1014.8 \pm 0.1$ & 0.180 \\
\hline DIF: $\beta C D:$ PVA $(2.5 \%)$ & $1142.5 \pm 0.2$ & 0.203 \\
\hline DIF: $\beta C D:$ PVA (5.0\%) & $1224.7 \pm 1.1$ & 0.218 \\
\hline DIF: $\beta C D:$ PVA (10.0\%) & $1241.5 \pm 0.5$ & 0.221 \\
\hline DIF: $\beta C D:$ PXM-188 (2.5\%) & $1134.3 \pm 0.4$ & 0.201 \\
\hline DIF: $\beta C D:$ PXM-188 (5.0\%) & $1241.5 \pm 2.0$ & 0.218 \\
\hline DIF: $\beta C D:$ PXM-188 (10.0\%) & $2317.0 \pm 1.0$ & 0.412 \\
\hline DIF: HP $\beta C D:$ PVA $(2.5 \%)$ & $1150.3 \pm 0.6$ & 0.204 \\
\hline DIF: HP $\beta C D:$ PVA (5.0\%) & $1241.5 \pm 1.0$ & 0.221 \\
\hline DIF: HPßCD: PVA (10.0\%) & $1267.1 \pm 1.5$ & 0.225 \\
\hline DIF: HP $\beta C D:$ PXM-188 (2.5\%) & $1309.2 \pm 0.2$ & 0.233 \\
\hline DIF: HP $\beta C D:$ PXM-188 (5.0\%) & $1404.4 \pm 0.3$ & 0.250 \\
\hline DIF: HP $\beta C D:$ PXM-188 (10.0\%) & $2407.3 \pm 0.6$ & 0.428 \\
\hline
\end{tabular}

\subsection{Solubility Studies}

The solubility data of DIF, binary and ternary systems of $\beta C D$ and HP $\beta C D$ are given in Table 2. Solubility of DIF was enhanced as a result of complexation with $\beta C D$ and HP $\beta C D$. At a ratio of DIF to cyclodextrin of 1:2, solubility was drastically increased from 44.60 to $450.36 \mu \mathrm{g} / \mathrm{mL}$ for $\beta C D$ and $907 \mu \mathrm{g} / \mathrm{mL}$ for $\mathrm{HP} \beta C D(p<0.05)$. There was no substantial increase in DIF solubility by increasing the amount of cyclodextrins further $(p>0.05)$. As such, the DIF/cyclodextrin complex at a ratio of 1:2 was chosen for subsequent study. A statistically significant $(p<0.05)$ improvement in DIF solubility was observed by the addition of hydrophilic polymer. The solubility further increased when polymer concentration was raised from $2.5 \%$ to $10.0 \%$. The solubility of DIF was the highest with PXM-188, followed by PVA and lastly, CMC-Na. PVA showed better solubility than CMC-Na due to better inclusion efficiency and improved complexation [41]. Maximum solubility was recorded for the DIF/HPßCD/PXM 188 ternary complex $(1259.50 \mu \mathrm{g} / \mathrm{mL})$, which was approximately 28 times that of drug solubility $(44.60 \mu \mathrm{g} / \mathrm{mL})$ and was considered statistically significant $(p<0.05)$. This could be attributed to having the least crystalline features and transformation of its ternary complexes into amorphous form [42].

Table 2. Solubility data of DIF, binary and ternary inclusion complexes. Mean $\pm \mathrm{SD}, \mathrm{N}=3$.

\begin{tabular}{ccc}
\hline \multirow{2}{*}{ DIF:CD (w/w) } & \multicolumn{2}{c}{ Solubility $(\mu \mathrm{g} / \mathrm{mL})$} \\
\cline { 2 - 3 } & $\beta \mathrm{CD}$ & HP $\beta C D$ \\
\hline $1: 0$ & $44.6 \pm 0.02$ & $44.6 \pm 0.02$ \\
$1: 1$ & $284.5 \pm 0.5$ & $765.5 \pm 0.5$ \\
$1: 2$ & $450.3 \pm 0.6$ & $907.5 \pm 0.5$ \\
$1: 4$ & $500.5 \pm 0.5$ & $940.4 \pm 0.5$ \\
$1: 2(2.5 \%$ PVA) & $789.6 \pm 0.5$ & $965.5 \pm 0.5$ \\
$1: 2(5.0 \%$ PVA) & $846.3 \pm 0.6$ & $1049.3 \pm 0.6$ \\
$1: 2(10.0 \%$ PVA) & $904.1 \pm 0.5$ & $1190.3 \pm 0.6$ \\
$1: 2(2.5 \%$ CMC-Na) & $692.1 \pm 0.3$ & $924.3 \pm 0.6$ \\
$1: 2(5.0 \%$ CMC-Na) & $723.6 \pm 0.6$ & $1000.5 \pm 0.5$ \\
$1: 2(10.0 \%$ CMC-Na) & $800.6 \pm 0.5$ & $1089.6 \pm 0.6$ \\
$1: 2(2.5 \%$ PXM-188) & $791.2 \pm 0.7$ & $998.5 \pm 0.5$ \\
$1: 2(5.0 \%$ PXM-188) & $894.4 \pm 0.5$ & $1181.6 \pm 0.6$ \\
$1: 2(10.0 \%$ PXM-188) & $930.0 \pm 0.5$ & $1259.5 \pm 0.5$ \\
\hline
\end{tabular}

Valero et al. reported ternary inclusion complexes of naproxen, $\beta C D$ and $P V P$, in which the polymer (PVP) has greater affinity for the naproxen/ $\beta C D$ binary systems than the free drug, and surrounded the binary system partially or completely through hydrogen bonding, resulting in pronounced increase in 
solubility [43]. The presence of CMC-Na did not enhance aqueous solubility of diflunisal considerably in the presence of cyclodextrins. This is further supported by the study of Alexanian et al. (2008) [44]. At low concentrations, CMC-Na interacts with the drug/CD inclusion complex in the same way as with micelles, but upon further increase in concentration, there is no significant increase in solubility, which could be possibly explained on the basis of its higher viscosity.

The ternary systems produced better complexation efficiency and improved solubility than that of binary systems. The polymer interacts with drug/CDs complexes through the outer surface of $\mathrm{CD}$ molecules and forms aggregates that are capable of solubilizing drugs and various hydrophobic entities [45].

\subsection{In Vitro Dissolution Study}

Figure 2a,b showed the dissolution of DIF, binary and ternary complexes with different contents of PVA, CMC-Na or PXM-188. DIF manifested the least dissolution, with approximately $50 \%$ of drug released after one hour. It could be observed that the percentage of drug release of both $\beta C D$ and $\mathrm{HP} \beta C D$ binary systems was comparatively higher than that of DIF. The addition of hydrophilic polymers further increased the drug release rate. The ternary system of DIF/HP $\beta C D / P X M-188$ yielded the highest dissolution. The ternary system with CMC-Na and PVA also showed improved dissolution than their corresponding binary systems, but less than PXM-188. The reason behind this is their viscosity, which hinders the diffusion of dissolution medium to the powdered product. Capello et al. (2001) reported that interaction of either the CD molecule or drug-CD complex with the hydrophilic polymers could lead to formation of aggregated hydrates in the solution, increasing the thickness of the diffusion layer and ultimately, slowing the drug release. The dissolution efficiency (DE) and time taken for $50 \%$ drug release $\left(T_{50 \%}\right)$ results are presented in Table 3 . The DE and $T_{50 \%}$ values were statistically analyzed using ANOVA (post hoc Tukey HSD test). The rate of in vitro dissolution for $\mathrm{DE}$ and $\mathrm{T}_{50 \%}$ values was statistically significant different when DIF and its inclusion complexes were analyzed. A statistically significant difference $(p<0.05)$ was observed when compared to the DE values of the binary kneaded mixture with pure DIF, whereas ternary complexes produced significant differences $(p<0.05)$ and improved DE as compared to the binary kneaded mixture. The longest $T_{50 \%}$ was observed for DIF as compared to its binary and ternary systems. The improved dissolution could be possibly described by the decrease in drug crystallinity of binary and ternary systems.

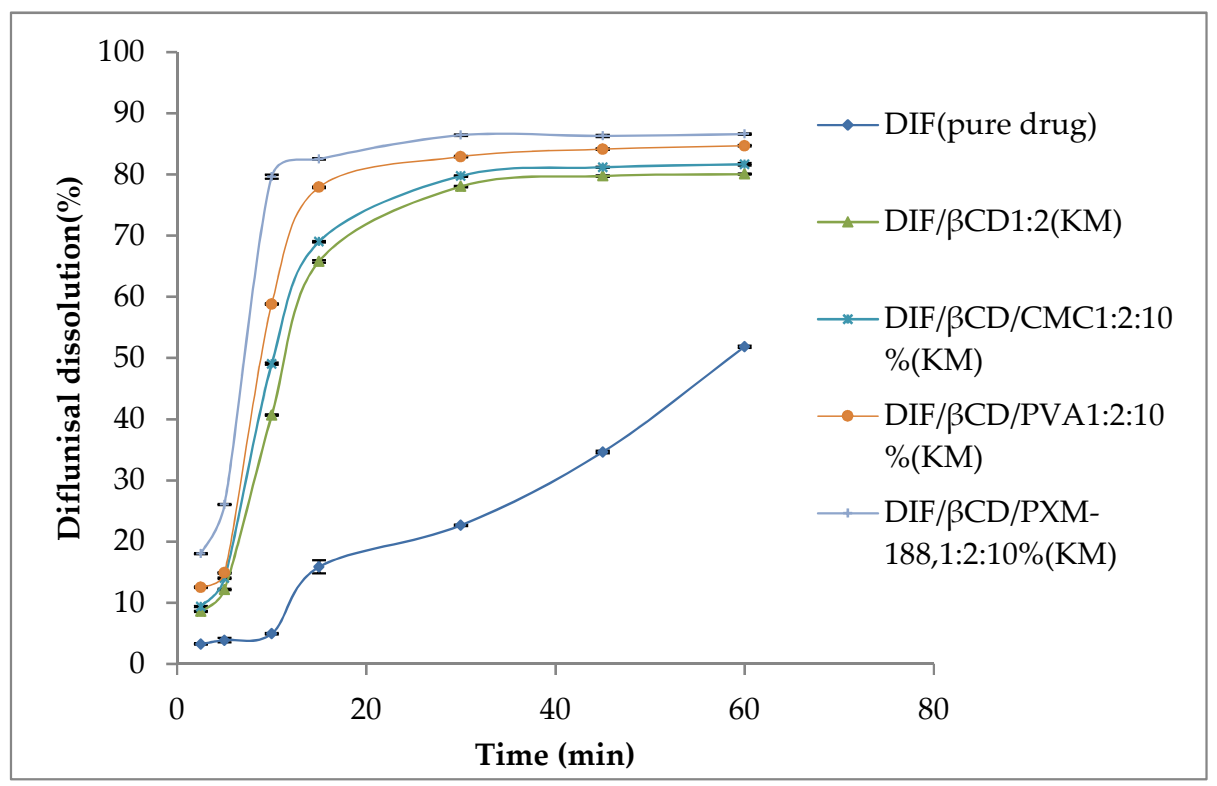

(a)

Figure 2. Cont. 


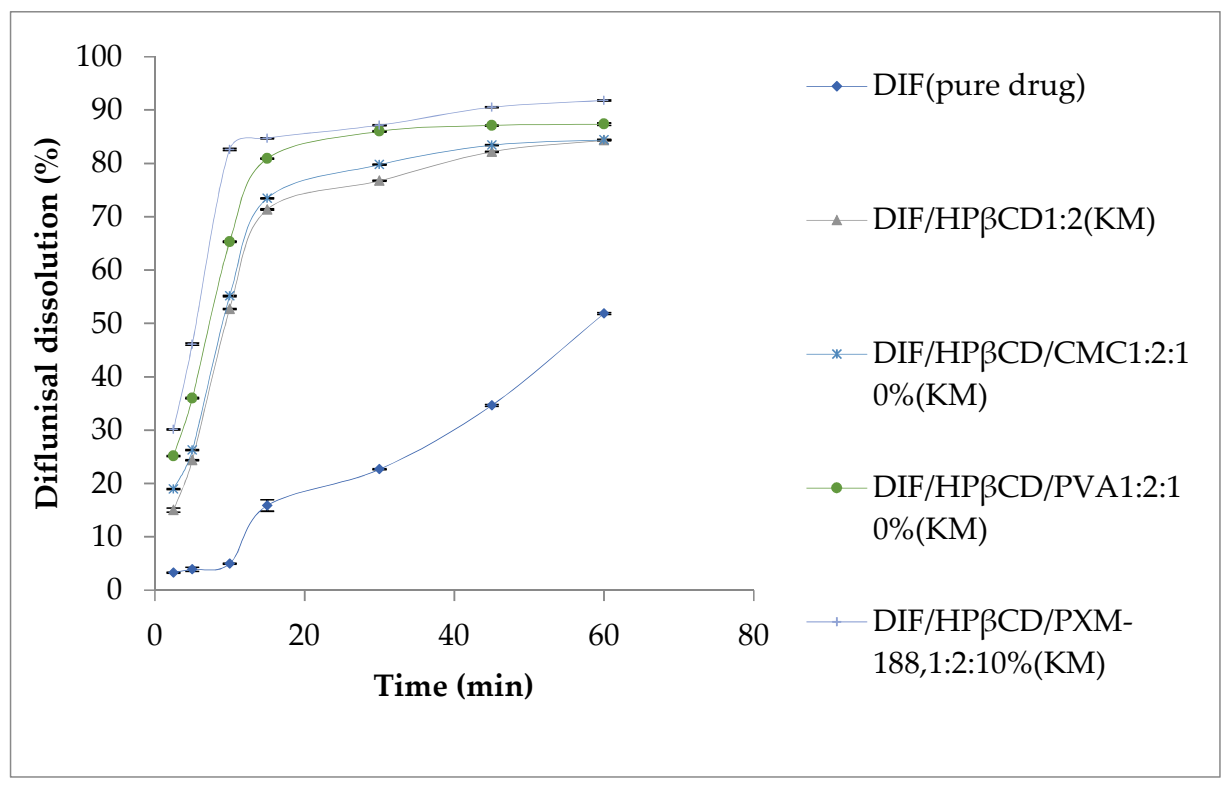

(b)

Figure 2. Mean dissolution profiles of DIF, binary and ternary systems with $\beta C D(\mathbf{a})$ and $\operatorname{HP} \beta C D(\mathbf{b})$. Mean $\pm \mathrm{SD}, \mathrm{N}=3$.

Table 3. The dissolution parameters of DIF, binary and ternary systems. Mean $\pm S D, N=3$.

\begin{tabular}{ccc}
\hline Samples & DE60 (\%) & $\boldsymbol{T}_{\mathbf{5 0} \%}$ (min) \\
\hline DIF & $24.2 \pm 0.3$ & $57.8 \pm 0.2$ \\
DIF: $\beta C D ~ 1: 2$ & $66.8 \pm 0.02$ & $11.3 \pm 0.03$ \\
DIF:HP $\beta C D ~ 1: 2$ & $66.7 \pm 0.02$ & $9.4 \pm 0.01$ \\
DIF: $\beta$ CD 1:2 (10\% PVA) & $71.6 \pm 0.05$ & $8.4 \pm 0.01$ \\
DIF: $\beta C D ~ 1: 2(10 \%$ CMC-Na) & $68.5 \pm 0.07$ & $10.8 \pm 0.01$ \\
DIF: $\beta C D ~ 1: 2(10 \%$ PXM-188) & $76.7 \pm 0.07$ & $6.2 \pm 0.02$ \\
DIF:HP $\beta C D ~ 1: 2(10 \%$ PVA) & $76.4 \pm 0.04$ & $7.65 \pm 0.01$ \\
DIF:HP $\beta C D ~ 1: 2(10 \%$ CMC-Na) & $69.3 \pm 0.03$ & $9.0 \pm 0.01$ \\
DIF:HP $\beta C D ~ 1: 2(10 \%$ PXM-188) & $81.0 \pm 0.01$ & $6.53 \pm 0.01$ \\
\hline
\end{tabular}

\subsection{Scanning Electron Microscopy (SEM)}

The scanning electron micrographs of DIF, $\beta C D, H P \beta C D$, PVA, CMC-Na, PXM-188, binary complexes and ternary complexes are given in Figure 3. DIF appeared as crystalline matter with bars of different lengths and widths (Figure $3 a)$ ). $\beta C D$ presented as large rhomboidal crystals with non-smooth surfaces (Figure $3 b$ ). HP $\beta C D$ exhibited oval shaped smooth particles of different sizes with concave depression (Figure 3d). The smaller particles were observed to adhere with the larger particles.

The DIF/ $\beta C D$ complex presented a rough surface with indefinite shape (Figure $3 c$ ). On the other hand, DIF was found to be included within HP $\beta C D$ for the DIF/HP $\beta C D$ complex. The shape of $\mathrm{HP} \beta C D$ changed from globular to a plane lamellar surface due to complex formation. The binary complex appeared as an amorphous structure of miscellaneously dispersed particles with asymmetrical morphology and coarse surface (Figure 3e). The SEM study indicated that the kneading method successfully converted DIF to an amorphous state in CD.

PVA appeared as large smooth surface particles due to its semi crystalline state (Figure 3f). CMC-Na exhibited irregular fiber structure of variable length (Figure 3g). PXM-188 showed a large globular form (Figure $3 h$ ). PVA produced a much coarser ternary system with HP $\beta C D$ than $\beta C D$. However, these systems appeared amorphous in the SEM micrographs (Figure $3 \mathrm{i}$ and 1 ). In the $\mathrm{DIF} / \beta C D / C M C-N a$ ternary complex, CMC-Na appeared to form a layer over DIF/ $\beta C D$ (Figure 3j), whereas DIF/HP $\beta C D / C M C-N a$ expressed more amorphous features due to the loss of original shape 
of the pure drug and HP $\beta C D$ (Figure 3m). In the DIF/ $\beta C D / P X M-188$ ternary complex, the crystal structure of PXM-188 disappeared and was adsorbed on the DIF/ $\beta C D$ surface (Figure $3 \mathrm{k}$ ), retaining little crystallinity. In the case of DIF/HP $\beta C D / P X M-188$, the ternary complex appeared as an amalgam and in aggregated form (Figure $3 n$ ).
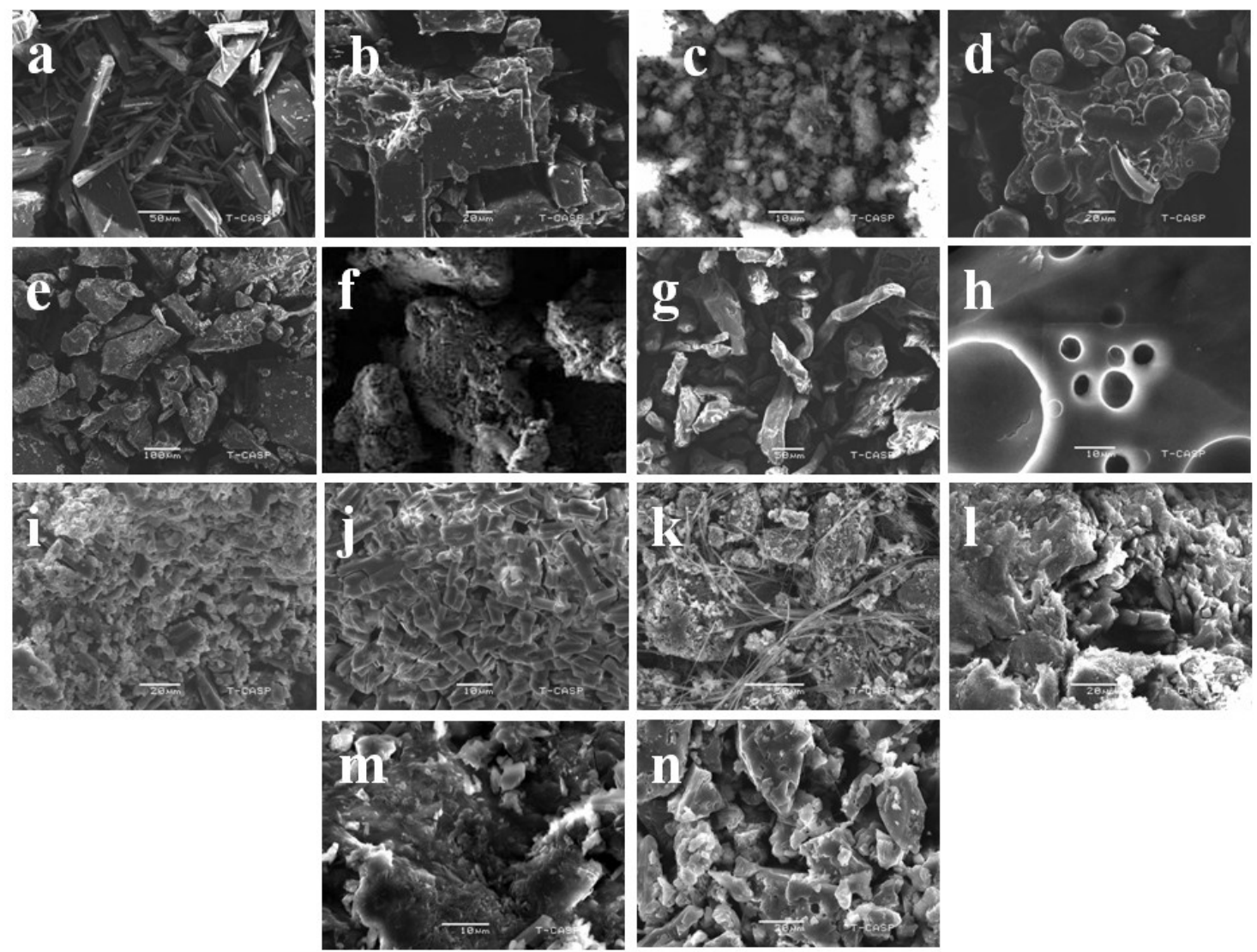

Figure 3. Scanning electron photomicrographs of (a) DIF; (b) $\beta C D$; (c) DIF/ $\beta C D$ (1:2); (d) HP $\beta C D$;

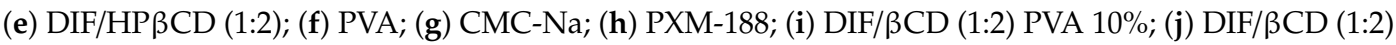
CMC-Na 10\%; (k) DIF/ßCD (1:2) PXM-188 10\%; (l) DIF/HPßCD (1:2) PVA 10\%; (m) DIF/HP $\beta C D ~(1: 2)$ CMC-Na 10\%; (n) DIF/HPßCD (1:2) PXM-188 10\%.

\subsection{Fourier-Transform Infrared Spectroscopy (FTIR).}

FTIR is a practical approach to investigate the drug-polymer interaction and formation of complex Figure 4 showed the FTIR spectra of DIF, CDs, hydrophilic polymers, binary and ternary systems. In the spectrum of DIF, a characteristic broad band appeared at $3152 \mathrm{~cm}^{-1}$ (due to aromatic $-\mathrm{C}-\mathrm{H}$ stretching and $\mathrm{OH}$ association and stretching), peaks at $1678 \mathrm{~cm}^{-1}$ (due to $-\mathrm{C}=\mathrm{O}$ stretching), $1664 \mathrm{~cm}^{-1}$ (due to stretching in the phenyl nucleus) and $1269 \mathrm{~cm}^{-1}$ (due to $C F$ stretch) (Figure $4 \mathrm{a}$ ). $\beta C D$ (Figure $4 \mathrm{~b}$ ) and HP $\beta C D$ (Figure 4c) spectra presented a strong and broad band between $3300-3400 \mathrm{~cm}^{-1}$, assigned to stretching vibrations of the hydroxyl group relative to intermolecular hydrogen bonds; the peak at $2920 \mathrm{~cm}^{-1}$ corresponded to stretching vibration of the aliphatic $\mathrm{C}-\mathrm{H}$ group; a band at $1600 \mathrm{~cm}^{-1}$ is indicative of deformation vibration of $-\mathrm{OH}$ group and $\mathrm{C}-\mathrm{O}$ stretching vibrations in ester; bands located at 1150 and $1030 \mathrm{~cm}^{-1}$ corresponded to the $\mathrm{C}-\mathrm{O}-\mathrm{C}$ stretching vibration [46].

All major peaks related to acetate and hydroxyl groups were observed in the spectrum of PVA (Figure 4d). The band due to intermolecular and intramolecular hydrogen bonding appeared between 3550 and $3200 \mathrm{~cm}^{-1}$. The vibrational band appearing between 2840 and $3000 \mathrm{~cm}^{-1}$ indicated stretching of $\mathrm{C}-\mathrm{H}$ from the alkyl group; the peaks appearing at $1750-1735 \mathrm{~cm}^{-1}$ represented $\mathrm{C}=\mathrm{O}$ and $\mathrm{C}-\mathrm{O}$ stretching from the acetate group; the band at $1087 \mathrm{~cm}^{-1}$ was due to $-\mathrm{C}-\mathrm{C}$ stretching of secondary alcohol; the band appearing at $851 \mathrm{~cm}^{-1}$ was due to the rocking mode of the $-\mathrm{CH}$ bond of PVA [47]. 
In the case of PXM-188 (Figure 4f), the spectrum showed peaks at $3465 \mathrm{~cm}^{-1}$ (due to -OH stretching), $2887 \mathrm{~cm}^{-1}$ (due to $-\mathrm{CH}$ stretching) and $1103 \mathrm{~cm}^{-1}$ (due to C-O stretching) [29,48]. In the spectrum of CMC-Na (Figure 4e), a strong peak could be visibly seen at $3443 \mathrm{~cm}^{-1}$ due to stretching vibration of hydroxyl group and the band area of $1000-1166 \mathrm{~cm}^{-1}$ indicated the presence of an ether bond. The carboxylate and methylene moiety gave peaks at 1635 and $2926.8 \mathrm{~cm}^{-1}$, respectively [48].

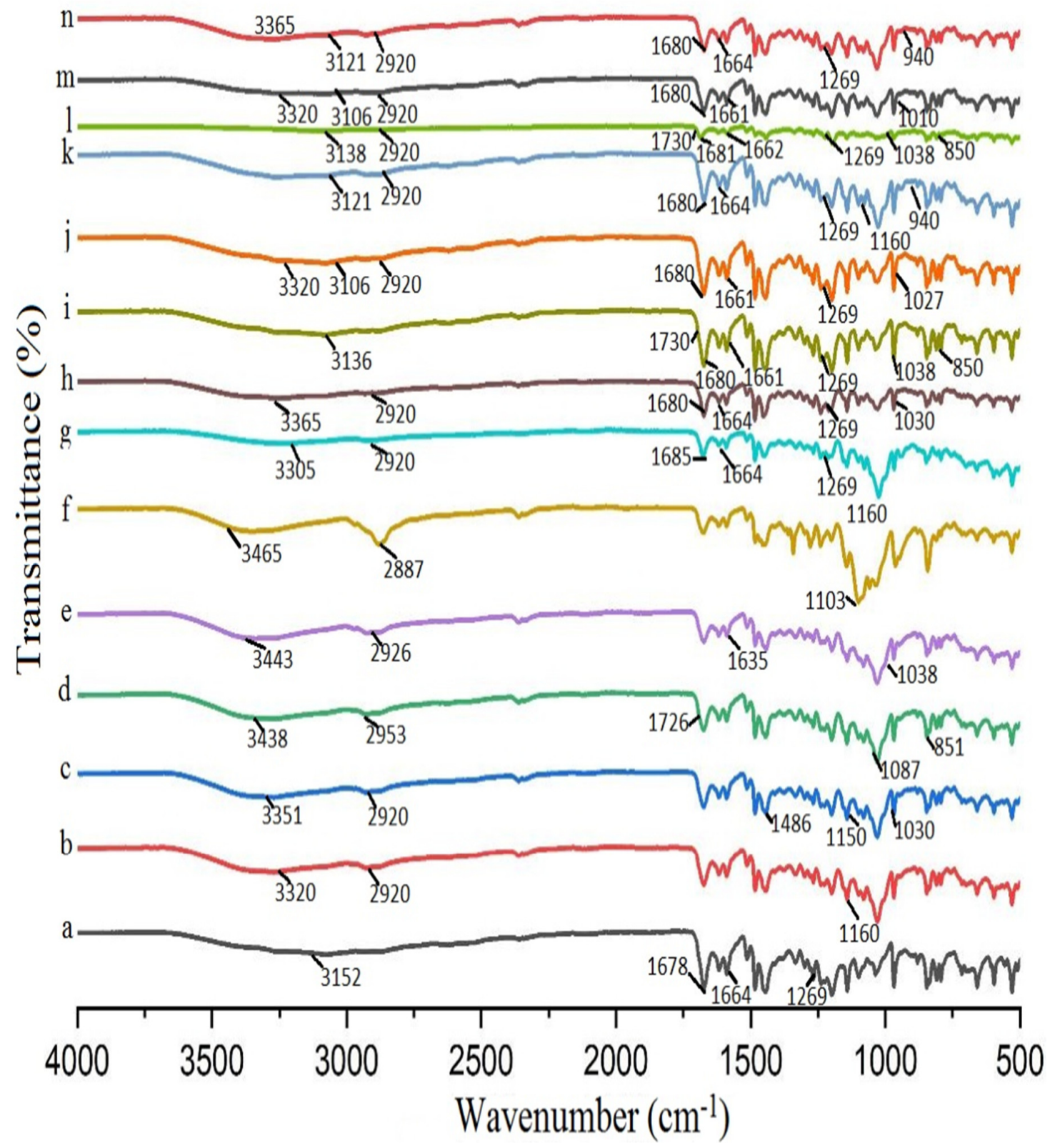

Figure 4. FTIR spectra of (a) DIF; (b) $\beta C D$; (c) HP $\beta C D$; (d) PVA; (e) CMC-Na; (f) PXM-188; (g) DIF/ $\beta C D$

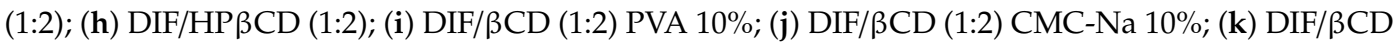

(1:2) PXM-188 10\%; (l) DIF/HP $\beta C D ~(1: 2)$ PVA 10\%; (m) DIF/HP $\beta C D ~(1: 2)$ CMC-Na 10\%; (n) DIF/HP $\beta C D$

(1:2) PXM-188 10\%.

The shifting and intensity changes of bands or peaks gave indication of complexation. There was a significant shifting of DIF peak from 3152 to $3305 \mathrm{~cm}^{-1}$ (for $\beta C D$ ) (Figure $4 \mathrm{~g}$ ) and $3365 \mathrm{~cm}^{-1}$ for $\mathrm{HP} \beta C D$ (Figure $4 \mathrm{~h}$ ). The shift could be attributed to modification in the hydrogen bonding network. The FTIR spectra of ternary systems signified some characteristic bands of individual elements, thus, reporting the formation of complexes with minor or insignificant alteration of functional groups of 
individual components. There were no dramatic changes in the peaks pattern of DIF, which confirms the absence of any chemical interaction among the components [49].

In the PVA ternary system (Figure 4i,l), a broad hydroxyl band appeared due to the shifting of the vibrational band (3220-3448 $\mathrm{cm}^{-1}$ ) towards a lower wave number, while the DIF peak at $3152 \mathrm{~cm}^{-1}$ was shifted to $3136 \mathrm{~cm}^{-1}$ with no significant change at other peaks, but their intensity was reduced, which is indicative of the suitability of ternary systems. The other peaks of PVA at 1726, 1087 and $851 \mathrm{~cm}^{-1}$ are shifted to 1730,1038 and $850 \mathrm{~cm}^{-1}$ in the complex, while the peak at $2925 \mathrm{~cm}^{-1}$ is found to be absent. Although the main peaks of DIF remained unchanged in the ternary system, the intensity of the peak that occurred due to $\mathrm{OH}$ association and stretching and aromatic - $\mathrm{CH}$ stretching reduced significantly, which indicates that ternary systems are quite suitable for enhancing complexation efficiency [50]. As for the ternary system with CMC-Na (both with $\beta C D$ and HP $\beta C D$ ), the characteristic peak of CMC-Na at $1038 \mathrm{~cm}^{-1}$ (due to carboxymethyl ether group stretching) diminished considerably and shifted to $1027 \mathrm{~cm}^{-1}$ (with $\beta C D$ ) (Figure 4j) and $1010 \mathrm{~cm}^{-1}$ (with $\mathrm{HP} \beta C D$ ) (Figure $4 \mathrm{~m}$ ), which indicated that CMC-Na might participate in the interaction through this chemical group. The characteristic band of DIF at $3152 \mathrm{~cm}^{-1}$, as a result of aromatic $-\mathrm{C}-\mathrm{H}$ stretching and $\mathrm{OH}$ association, was shifted towards a lower wave number at $3106 \mathrm{~cm}^{-1}$, while all other peaks did not undergo a significant shift. No new peak was observed in the ternary system, indicative of the compatibility between the drug and carriers.

As for the DIF/ $\beta C D / P X M-188$ (Figure $4 \mathrm{k}$ ) ternary system, the characteristic DIF peak at $3152 \mathrm{~cm}^{-1}$ shifted to $3122 \mathrm{~cm}^{-1}$, an indication of hydrogen bonding resulting in an almost flat region. The DIF peak at $1269 \mathrm{~cm}^{-1}$ was significantly reduced and completely masked in DIF/HP $\beta C D / P X M-188$, which might be due to insertion of DIF in the molecular cage of cyclodextrin in the presence of PXM-188 (Figure $4 \mathrm{n}$ ). The peak of PXM-188 at $2887 \mathrm{~cm}^{-1}$ vanished, probably due to strong interaction with cyclodextrins. The appearance of a band at $940 \mathrm{~cm}^{-1}$ in the spectra of ternary systems of cyclodextrins with PXM-188 was due to the vibration of an $\alpha(1 \rightarrow 4)$ glucopyranose ring of cyclodextrins, thus, reinforcing the grafting of cyclodextrin onto the polymeric network.

The absence of any new peak in the FTIR spectra indicated that there was no chemical incompatibility among the components, only the vanishing and reduction in peak intensity as a result of complexation.

\subsection{Differential Scanning Calorimetry (DSC)}

The host-guest interaction can be better evaluated by DSC. The melting point peak of the drug is either shifted or disappears as a result of inclusion within the cyclodextrin molecular cage [51,52]. Figure 5 showed the thermograms of DIF, $\beta C D, H P \beta C D$, hydrophilic polymers and the binary and ternary systems. DIF showed a single endothermic peak around $210{ }^{\circ} \mathrm{C}$ (Figure $5 \mathrm{a}$ ). $\beta C D$ (Figure $5 b$ ) and $\mathrm{HP} \beta C D$ (Figure 5c) manifested broad endothermic peaks at 92.4 and $61.8^{\circ} \mathrm{C}$, indicating loss of water molecules due to the dehydration process and melting peaks at 325.2 and $340.2{ }^{\circ} \mathrm{C}$, respectively. PVA showed an endothermic peak at $45.2^{\circ} \mathrm{C}$ (Figure 5d). CMC-Na showed an endothermic peak at $130.2{ }^{\circ} \mathrm{C}$ and exothermic peak at $274{ }^{\circ} \mathrm{C}$ (Figure 5e), while PXM-188 revealed an endothermic peak at about $56.1^{\circ} \mathrm{C}$ (Figure 5f).

The reduction in the intensity and shifting of DIF peaks to 212.2 and $214{ }^{\circ} \mathrm{C}$ was observed in DIF/ $\beta C D$ and DIF/HP $\beta C D$ binary complexes (Figure $4 \mathrm{~g}, \mathrm{~h}$ ). The drug peak was shifted to $213.2^{\circ} \mathrm{C}$ for $\mathrm{DIF} / \beta \mathrm{CD} / \mathrm{PVA}$

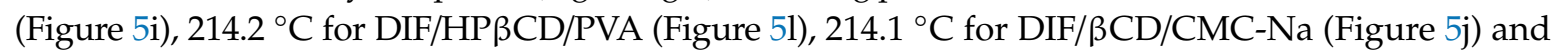
$216.1^{\circ} \mathrm{C}$ for DIF/HP $\beta C D / C M C-N a$ ternary complexes (Figure $5 \mathrm{~m}$ ). For the DIF/ $\beta C D / P X M-188$ ternary system, the intensity of the drug peak was remarkably reduced and shifted to $215.1^{\circ} \mathrm{C}$ (Figure $5 \mathrm{k}$ ). An almost flat region was obtained with DIF/HP $\beta C D / P X M-188$, indicating reduced crystallinity and improved complexation with $\mathrm{HP} \beta C D$ (Figure $5 n$ ). 


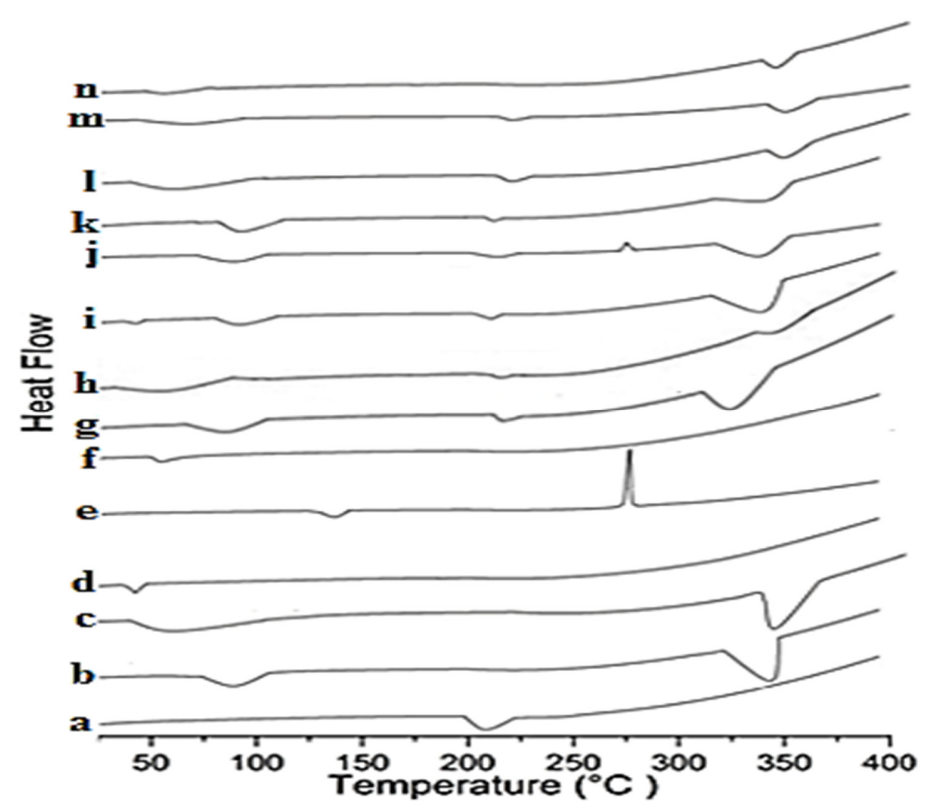

Figure 5. DSC thermograms of (a) DIF; (b) $\beta C D$; (c) HP $\beta C D$; (d) PVA; (e) CMC-Na; (f) PXM-188; (g) DIF/ $\beta C D$ (1:2); (h) DIF/HP $\beta C D$ (1:2); (i) DIF/ $\beta C D$ (1:2) PVA 10\%; (j) DIF/ $\beta C D ~(1: 2)$ CMC-Na 10\%; (k) DIF//CD (1:2) PXM-188 10\%; (1) DIF/HP $\beta C D$ (1:2) PVA 10\%; (m) DIF/HP $\beta C D ~(1: 2)$ CMC-Na 10\%; (n) DIF/HPßCD (1:2) PXM-188 10\%.

\subsection{Powder X-ray Diffractometry (XRD)}

Figure 6 showed the powder XRD patterns for DIF, CDs, hydrophilic polymers and the binary and ternary systems. DIF exhibited crystalline nature, with characteristic peaks at $2 \theta$ values of $13.5^{\circ}, 14.4^{\circ}$, $16.9^{\circ}$ and two peaks of lower intensity at $26.5^{\circ}$ and $27.9^{\circ}$ (Figure $6 \mathrm{a}$ ). $\beta C D$ displayed crystalline features (Figure 6b), while HP $\beta C D$ appeared to be in an amorphous state (Figure 6c). PVA and CMC-Na are amorphous (Figure 5d,e), whereas PXM-188 is crystalline in nature (Figure 6f).

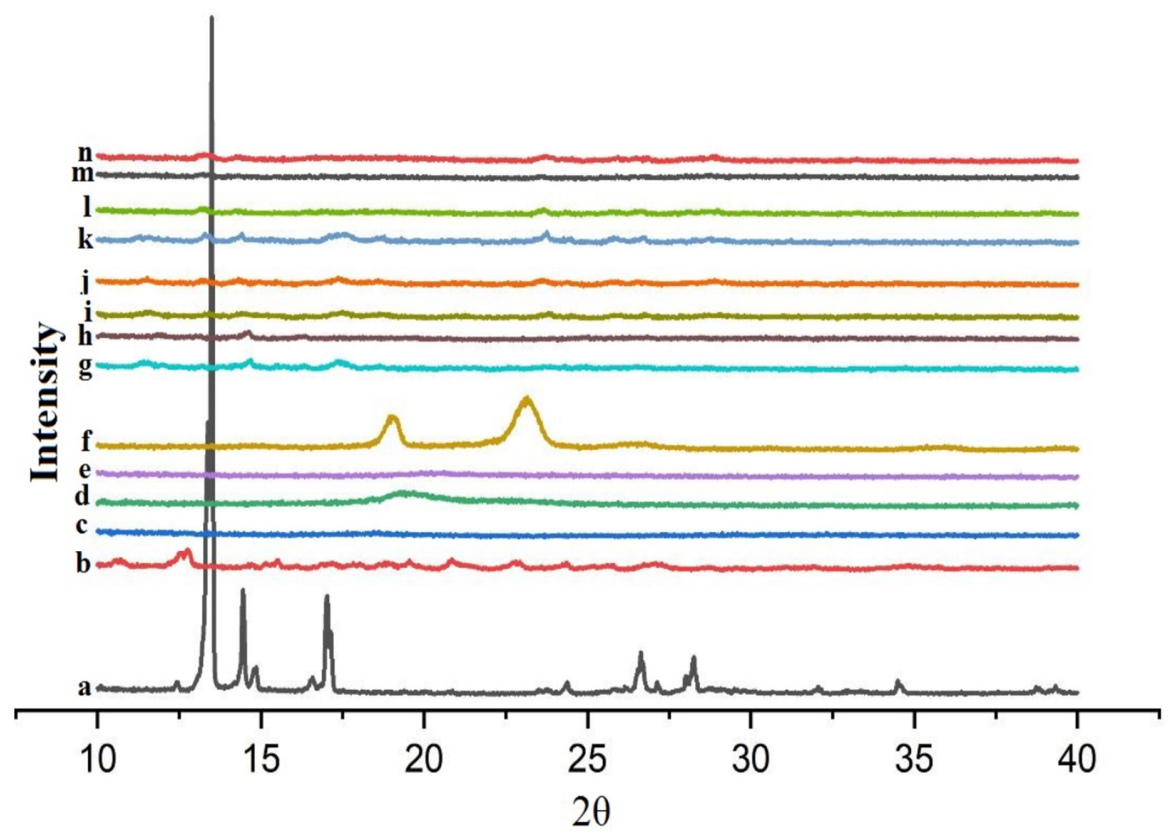

Figure 6. XRD diffractograms of (a) DIF; (b) $\beta C D$; (c) HP $\beta C D$; (d) PVA; (e) CMC-Na; (f) PXM-188;

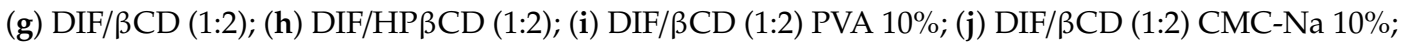
(k) DIF//CD (1:2) PXM-188 10\%; (l) DIF/HP $\beta C D$ (1:2) PVA 10\%; (m) DIF/HP $\beta C D ~(1: 2)$ CMC-Na 10\%; (n) DIF/HPßCD (1:2) PXM-188 10\%. 
In the binary systems of $\beta C D$, the drug peaks at $26.5^{\circ}$ and $27.9^{\circ}$ vanished and the inclusion complex showed a reduction in the number of crystalline peaks with greater degree of amorphousness (Figure $6 \mathrm{~g}$ ). On the other hand, the drug peaks at $26.5^{\circ}$ and $27.9^{\circ}$ in the binary system of HP $\beta C D$ also disappeared. The binary system of HP $\beta C D$ showed further reduction in the crystalline peaks and expressed greater amorphousness. It is evident from the diffractograms of binary systems that higher C.E could be achieved using HP $\beta C D$ (Figure $6 h$ ).

Diffractograms for ternary systems showed more amorphousness than the binary systems. Although the peaks were detectable in ternary systems, their intensity was reduced and appeared as amorphous. For the ternary system with $\beta C D / P V A$, the characteristic peak of PVA at $19.3^{\circ}$ broadened, followed by a reduction in intensity, indicating amorphous nature (Figure 6i). For the ternary system with $\mathrm{HP} \beta \mathrm{CD} / \mathrm{PVA}$, there was more broadening as compared to that of $\beta C D / \mathrm{PVA}$ and the main peak of PVA at $19.3^{\circ}$ completely vanished (Figure 61 ). In the $\beta C D / C M C-N a$ ternary systems, the peak of CMC-Na at $19.8^{\circ}$ diminished significantly and an almost flat region was obtained (Figure 6j). In addition, the intensity of drug peak at $13.2^{\circ}$ decreased and the inclusion complex appeared to be amorphous. The same trend was observed with $\mathrm{HP} \beta \mathrm{CD} / \mathrm{CMC}-\mathrm{Na}$; the characteristic peak of CMC-Na at $19.8^{\circ}$ vanished and the peak intensity at $13.5^{\circ}$ further reduced (Figure $6 \mathrm{~m}$ ). The inclusion complex showed greater amorphousness as compared to the $\beta C D / C M C-N a$ ternary system. PXM-188 showed two crystalline peaks at $18.9^{\circ}$ and $23.1^{\circ}$, while the ternary system of PXM-188/CDs showed a reduction in crystalline peaks of PXM-188 and intensity of drug peak at $13.5^{\circ}$ (Figure $6 \mathrm{k}, \mathrm{n}$ ). Some crystalline peaks of PXM-188/ $\beta C D$ vanished and preparations appeared to be amorphous in nature but PXM-188/HP $\beta C D$ formulations showed greater amorphousness.

The reduction in intensity and broadening of peaks could be better attributed to nanosized particles which cause insufficient diffraction centers, which ultimately lead to peak broadening phenomenon [53]. A correlation between degree of crystallinity and height of peak could be established according to the criterion of Hodge et al. [54]. The release of water molecules (enthalpy-rich) from the cyclodextrin cavity is the motivational force for complex formation [20,55]. These water molecules exhibited higher enthalpy and could not fit properly in the cavity. To stabilize the systems, these more polar molecules were replaced by less polar drug molecules.

The XRD data show that the typical crystalline peaks of DIF were detectable (less in number and reduced intensity). These findings suggest the presence of fewer amounts of crystalline drugs in the system (either binary or ternary, with different extents). DIF appeared to be more amorphous with intense molecular mobility and high energy than the crystalline form, which contributes to improved apparent solubility and dissolution. Binary systems with HP $\beta C D$ gave better solubility and dissolution data than that of $\beta C D$, which is further improved by addition of hydrophilic polymers.

\section{Conclusions}

$\mathrm{HP} \beta C D$ yields better results than those of $\beta C D$. Increase in solubility and dissolution of DIF were found with the addition of hydrophilic polymers (PVA, CMC-Na and PXM-188) to binary systems of $\mathrm{DIF} / \beta C D$ and DIF/HP $\beta C D$. Ternary systems with PXM-188 presented comparatively more superior performance in enhancing solubility and dissolution of DIF.

Author Contributions: Conceptualization, M.B., S.A. and H.K.S.; Data curation, H.K.S.; Formal analysis, H.K.S., M.B. and S.A.; Investigation, M.B., I.U.K., P.A.S., J.A. and U.F.G.; Methodology, H.K.S., M.B. and S.A.; Project administration, H.K.S.; Resources, M.I., W.H.A., S.A.M., I.U.K., P.A.S., I.K., J.A., U.F.G. and M.S.I.; Supervision, H.K.S.; Writing—original draft, M.B.; Writing—review and editing, K.K.P. All authors have read and agreed to the published version of the manuscript.

Funding: This research was funded by Higher education commission (HEC), Pakistan, grant number 417-71915-2MD4-010 (50039076) and the APC was borne by authors themselves.

Acknowledgments: The authors thank Higher Education Commission (HEC), Pakistan for the grant no. 417-71915-2MD4-010 (50039076).

Conflicts of Interest: There is no conflict of interest among the listed authors. 


\section{References}

1. Krishnaiah, Y.S. Pharmaceutical technologies for enhancing oral bioavailability of poorly soluble drugs. J. Bioequiv. Bioavailab. 2010, 2, 28-36. [CrossRef]

2. Kumar, A.; Sahoo, S.K.; Padhee, K.; Kochar, P.; Satapathy, A.; Pathak, N. Review on solubility enhancement techniques for hydrophobic drugs. Pharm. Glob. 2011, 3, 1-7.

3. Rong, W.T.; Lu, Y.P.; Tao, Q.; Guo, M.; Lu, Y.; Ren, Y. Hydroxypropyl-sulfobutyl-beta-cyclodextrin improves the oral bioavailability of edaravonebymodulating drug efflux pump of enterocytes. J. Pharm. Sci. 2014, 103, 730-742. [CrossRef] [PubMed]

4. Savjani, K.T.; Gajjar, A.K.; Savjani, J.K. Drug solubility: Importance andenhancement techniques. ISRN Pharm. 2012, 5, 1-10.

5. Crupi, V.; Majolino, D.; Mele, A.; Rossi, B.; Trotta, F.; Venuti, V. Modelling the interplay between covalent and physical interactions in cyclodextrin-based hydrogel: Effect of water confinement. Soft Matter. 2013, 9, 6457-6464. [CrossRef]

6. Ferrati, S.; Nicolov, E.; Bansal, S.; Hosali, S.; Landis, M.; Grattoni, A. Docetaxel/2-hydroxypropyl $\beta$-cyclodextrin inclusion complex increases docetaxel solubility and release from a nanochannel drug delivery system. Curr. Drug Targets 2015, 16, 1645-1649. [CrossRef]

7. Leuner, C.; Dressman, J. Improving drug solubility for oral delivery using solid dispersions. Eur. J. Pharm. Biopharm. 2000, 50, 47-60. [CrossRef]

8. Li, C.; Fleisher, D.; Li, L.; Schwier, J.R.; Sweetana, S.A.; Vasudevan, V.; Zornes, L.L.; Pao, L.H.; Zhou, S.Y.; Stratford, R.E. Regional-dependent intestinal absorption and meal composition effects on systemic availability of LY303366, a lipopeptide antifungal agent, in dogs. J. Pharm. Sci. 2001, 90, 47-57. [CrossRef]

9. Peres, L.B.; Peres, L.B.; de Araújo, P.H.; Sayer, C. Solid lipid nanoparticles for encapsulation of hydrophilic drugs by an organic solvent free double emulsion technique. Colloid Surf. B. 2016, 140, 317-323. [CrossRef]

10. Loftsson, T.; Duchene, D. Cyclodextrins and their pharmaceutical applications. Int. J. Pharm. 2007, 329, 1-11. [CrossRef] [PubMed]

11. Stancanelli, R.; Ficarra, R.; Cannavà, C.; Guardo, M.; Calabrò, M.L.; Ficarra, P.; Ottanà, R.; Maccari, R.; Crupi, V.; Majolino, D.; et al. UV-vis and FTIR-ATR characterization of 9-fluorenon-2-carboxyester/(2-hydroxypropyl)$\beta$-cyclodextrin inclusion complex. J. Pharm. Biomed. 2008, 47, 704-709. [CrossRef]

12. Vasconcelos, T.; Sarmento, B.; Costa, P. Solid dispersions as strategy to improve oral bioavailability of poor water soluble drugs. Drug Discov. Today 2007, 12, 1068-1075. [CrossRef]

13. Stella, V.J.; He, Q. Cyclodextrins. Toxicol. Pathol. 2008, 36, 30-42. [CrossRef]

14. Reddy, M.N.; Rehana, T.; Ramakrishna, S.; Chowdary, K.P.R.; Diwan, P.V. Beta-cyclodextrin complexes of celecoxib: Molecular-modeling, characterization, and dissolution studies. AAPS Pharm. Sci. 2004, 6, 68-76. [CrossRef]

15. Asbahr, A.C.C.; Franco, L.; Barison, A.; Silva, C.W.; Ferraz, H.G.; Rodrigues, L.N. Binary and ternary inclusion complexes of finasteride in HP $\beta C D$ and polymers: Preparation and characterization. Bioorg. Med. Chem. 2009, 17, 2718-2723. [CrossRef]

16. Lu, Y.; Zhang, T.; Tao, J.; Ji, G.; Wang, S. Preparation, characterization, and pharmacokinetics of the inclusion complex of genipin- $\beta$-cyclodextrin. Drug Dev. Ind. Pharm. 2009, 35, 1452-1459. [CrossRef]

17. Shen, T.Y. Chemical and pharmacological properties of diflunisal. Pharmacotherapy 1983, 2, 3S-8S. [CrossRef]

18. Lincoln, S.F.; Coates, J.H.; Doddridge, B.G.; Hounslow, A.M. The inclusion of the drug diflunisal by alpha-and beta-cyclodextrins. A nuclear magnetic resonance and ultraviolet spectroscopic study. J. Incl. Phenom. 1987, 5, 49-53. [CrossRef]

19. Lincoln, S.F.; Hounslow, A.M.; Coates, J.H.; Villani, R.P.; Schiller, R.L. The inclusion of diflunisal by $\gamma$-cyclodextrin and permethylated $\beta$-cyclodextrin. A UV-visible and $19 \mathrm{~F}$ nuclear magnetic resonance spectroscopic study. J. Incl. Phenom. 1988, 6, 183-191. [CrossRef]

20. Sideris, E.E.; Valsami, G.N.; Koupparis, M.A.; Macheras, P.E. Studies on the interaction of diflunisal ion with cyclodextrins using ion-selective electrode potentiometry. Eur. J. Pharm. Sci. 1999, 7, 271-278. [CrossRef]

21. Zugasti, M.E.; Zornoza, A.; del Mar Goni, M.; Isasi, J.R.; Vélaz, I.; Martín, C.; Sánchez, M.; Martínez-Ohárriz, M.C. Influence of soluble and insoluble cyclodextrin polymers on drug release from hydroxypropyl methylcellulose tablets. Drug Dev. Ind. Pharm. 2009, 35, 1264-1270. [CrossRef] [PubMed] 
22. Najib, N.M.; Suleiman, M.S. Characterization of a diflunisal polyethylene glycol solid dispersion system. Int. J. Pharm. 1989, 51, 225-232. [CrossRef]

23. Zhong, Z.; Yang, X.; Fu, X.B.; Yao, Y.F.; Guo, B.H.; Huang, Y.; Xu, J. Crystalline inclusion complexes formed between the drug diflunisal and block copolymers. Chin. Chem. Lett. 2017, 28, 1268-1275. [CrossRef]

24. Pignatello, R.; Ferro, M.; De Guidi, G.; Salemi, G.; Vandelli, M.A.; Guccione, S.; Geppi, M.; Forte, C.; Puglisi, G. Preparation, characterisation and photosensitivity studies of solid dispersions of diflunisal and Eudragit RS100 ${ }^{\circledR}$ and RL100 ${ }^{\circledR}$. Int. J. Pharm. 2001, 218, 27-42. [CrossRef]

25. Rodriguez-Espinosa, C.; Martinez-Oharriz, M.C.; Martin, C.; Goni, M.M.; Velaz, I.; Sanchez, M. Dissolution kinetics for coprecipitates of diflunisal with PVP K30. Eur. J. Drug Metab. Ph. 1998, 23, 109-112. [CrossRef]

26. Évora, A.O.; Castro, R.A.; Maria, T.M.; Rosado, M.T.; Ramos Silva, M.; Matos Beja, A.; Canotilho, J.; Eusébio, M.E. Pyrazinamide-diflunisal: A new dual-drug co-crystal. Cryst. Growth Des. 2011, 11, 4780-4788. [CrossRef]

27. Wang, L.; Tan, B.; Zhang, H.; Deng, Z. Pharmaceutical cocrystals of diflunisal with nicotinamide or isonicotinamide. Org. Process Res. Dev. 2013, 17, 1413-1418. [CrossRef]

28. Mura, P.; Faucci, M.T.; Bettinetti, G.P. The influence of polyvinylpyrrolidone on naproxen complexation with hydroxypropyl-ß-cyclodextrin. Eur. J. Pharm. Sci. 2001, 13, 187-194. [CrossRef]

29. Ghareeb, M.M.; Abdulrasool, A.A.; Hussein, A.A.; Noordin, M.I. Kneading technique for preparation of binary solid dispersion of meloxicam with poloxamer 188. AAPS Pharm. Sci. Tech. 2009, 10, 1206-1215. [CrossRef]

30. Kono, H.; Onishi, K.; Nakamura, T. Characterization and bisphenolA adsorption capacity of $\beta$-cyclodextrincarboxymethylcellulose-based hydrogels. Carbohydr. Polym. 2013, 98, 784-792. [CrossRef]

31. Ribeiro, L.; Loftsson, T.; Ferreira, D.; Veiga, F. Investigation and physicochemical characterization of vinpocetine-sulfobutyl ether $\beta$-cyclodextrin binary and ternary complexes. Chem. Pharm. Bull. 2003, 51, 914-922. [CrossRef]

32. Kaur, I.P.; Kapil, M.; Smitha, R.; Aggarwal, D. Development of topically effective formulations of acetazolamide using HP- $\beta$-CD-polymer co-complexes. Curr. Drug Deliv. 2004, 1, 65-72. [CrossRef]

33. Gundogdu, E.; Koksal, C.; Karasulu, E. Comparison of cefpodoxime proxetil release and antimicrobial activity from tablet formulations: Complexation with hydroxypropyl- $\beta$-cyclodextrin in the presence of water soluble polymer. Drug Dev. Ind. Pharm. 2012, 38, 689-696. [CrossRef]

34. Sharma, A.; Jain, C.P.; Tanwar, Y.S. Preparation and characterization of solid dispersions of carvedilol with poloxamer 188. J. Chil. Chem. Soc. 2013, 58, 1553-1557. [CrossRef]

35. Higuchi, T.K.A.C. A phase solubility technique. Adv. Anal. Chem. Instrum. 1965, 4, 117-211.

36. Bera, H.; Chekuri, S.; Sarkar, S.; Kumar, S.; Muvva, N.B.; Mothe, S.; Nadimpalli, J. Novel pimozide- $\beta$ cyclodextrin-polyvinylpyrrolidone inclusion complexes for Tourette syndrome treatment. J. Mol. Liq. 2016, 215, 135-143. [CrossRef]

37. Loh, G.O.K.; Tan, Y.T.F.; Peh, K.K. Enhancement of norfloxacin solubility via inclusion complexation with $\beta$-cyclodextrin and its derivative hydroxypropyl- $\beta$-cyclodextrin. Asian J. Pharm. Sci. 2016, 11, 536-546. [CrossRef]

38. Khan, S.; Batchelor, H.; Hanson, P.; Perrie, Y.; Mohammed, A.R. Physicochemical characterisation, drug polymer dissolution and in vitro evaluation of phenacetin and phenylbutazone solid dispersions with polyethylene glycol 8000. J. Pharm. Sci. 2011, 100, 4281-4294. [CrossRef]

39. Gururaj, A.E.; Belakavadi, M.; Venkatesh, D.A.; Marmé, D.; Salimath, B.P. Molecular mechanisms of anti-angiogenic effect of curcumin. Biochem. Biophys. Res. 2002, 297, 934-942. [CrossRef]

40. Brewster, M.E.; Loftsson, T. Cyclodextrins as pharmaceutical solubilizers. Adv. Drug Deliv. Rev. 2007, 59, 645-666. [CrossRef]

41. Ratna, J.V.; Annama Devi, G.S.; Chalumuru, R. Effect of PVA on HP- $\beta$-CD inclusion complexes of diclofenac for enhancing its dissolution rate. J. Glob. Trends Pharm. Sci. 2012, 3, 708-713.

42. Ansari, M.T.; Hussain, A.; Nadeem, S.; Majeed, H.; Saeed-Ul-Hassan, S.; Tariq, I.; Mahmood, Q.; Khan, A.K.; Murtaza, G. Preparation and characterization of solid dispersions of artemether by freeze-dried method. Biomed. Res. Int. 2015. [CrossRef] [PubMed]

43. Valero, M.; Pérez-Revuelta, B.I.; Rodríguez, L.J. Effect of PVP K-25 on the formation of the naproxen: $\beta$-ciclodextrin complex. Int. J. Pharm. 2003, 97-110. [CrossRef] 
44. Alexanian, C.; Papademou, H.; Vertzoni, M.; Archontaki, H.; Valsami, G. Effect of pH and water-soluble polymers on the aqueous solubility of nimesulide in the absence and presence of $\beta$-cyclodextrin derivatives. J. Pharm. Pharmacol. 2008, 60, 1433-1439. [CrossRef]

45. Cappello, B.; Carmignani, C.; Iervolino, M.; La Rotonda, M.I.; Saettone, M.F. Solubilization of tropicamide by hydroxypropyl- $\beta$-cyclodextrin and water-soluble polymers: In vitro/in vivo studies. Int. J. Pharm. 2001, 213, 75-81. [CrossRef]

46. Marcolino, A.I.P.; Macedo, L.B.; Nogueira-Librelotto, D.R.; Fernandes, J.R.; Bender, C.R.; Wust, K.M.; Rolim, C.M.B. Preparation, characterization and in vitro cytotoxicity study of dronedarone hydrochloride inclusion complexes. Mater. Sci. Eng. C 2019, 100, 48-61. [CrossRef]

47. Mansur, H.S.; Sadahira, C.M.; Souza, A.N.; Mansur, A.A. FTIR spectroscopy characterization of poly (vinyl alcohol) hydrogel with different hydrolysis degree and chemically crosslinked with glutaraldehyde. Mater. Sci. Eng. 2008, 28, 539-548. [CrossRef]

48. Malik, N.S.; Ahmad, M.; Minhas, M.U. Cross-linked $\beta$-cyclodextrin and carboxymethyl cellulose hydrogels for controlled drug delivery of acyclovir. PLoS ONE 2017, 12, e0172727. [CrossRef]

49. Dandawate, P.R.; Vyas, A.; Ahmad, A.; Banerjee, S.; Deshpande, J.; Swamy, K.V.; Sarkar, F.H. Inclusion complex of novel curcumin analogue CDF and $\beta$-cyclodextrin (1: 2) and its enhanced in vivo anticancer activity against pancreatic cancer. Pharm. Res. 2012, 29, 1775-1786. [CrossRef]

50. Rajendran, S.; Sivakumar, M.; Subadevi, R.; Wu, N.L.; Lee, J.Y. Electrochemical investigations on the effect of dispersoid in PVA based solid polymer electrolytes. J. Appl. Polym. Sci. 2007, 103, 3950-3956. [CrossRef]

51. Doiphode, D.; Gaikwad, S.; Pore, Y.; Kuchekar, B.; Late, S. Effect of $\beta$-cyclodextrincomplexation on physicochemical properties of zaleplon. J. Incl. Phenom. Macrocycl. Chem. 2008, 62, 43-50. [CrossRef]

52. Shah, M.; Pore, Y.; Dhawale, S.; Burade, K.; Kuchekar, B. Physicochemical characterization of spray dried ternary micro-complexes of cefuroxime axetil with hydroxypropyl- $\beta$-cyclodextrin. J. Incl. Phenom. Macrocycl. Chem. 2013, 76, 391-401. [CrossRef]

53. Pathak, T.K.; Vasoya, N.H.; Lakhani, V.K.; Modi, K.B. Structural and magnetic phase evolution study on needle-shaped nanoparticles of magnesium ferrite. Ceram. Int. 2010, 36, 275-281. [CrossRef]

54. Hodge, R.M.; Edward, G.H.; Simon, G.P. Water absorption and states of water in semicrystalline poly (vinyl alcohol) films. Polymer 1996, 37, 1371-1376. [CrossRef]

55. Ugwu, S.O.; Alcala, M.J.; Bhardwaj, R.; Blanchard, J. Characterization of the complexation of diflunisal with hydroxypropyl- $\beta$-cyclodextrin. J. Pharm. Biomed. Anal. 1999, 19, 391-397. [CrossRef] 